\title{
Ras Activated ERK and PI3K Pathways Differentially Affect Directional Movement of Cultured Fibroblasts
}

\author{
Leandra Sepe ${ }^{a, b, c} \quad$ Maria Carla Ferrari ${ }^{a, b, c} \quad$ Concita Cantarella ${ }^{d} \quad$ Francesca Fiorettia $^{a}$ \\ Giovanni Paolella $a^{a, b}$
}

a'Dipartimento di Biochimica e Biotecnologie mediche, Universita' degli Studi di Napoli Federico II, Napoli; 'beinge Biotecnologie Avanzate, Napoli; 'Laboratorio di Medicina Molecolare, Facolta' di Medicina e Chirurgia, Universita' di Salerno, Baronissi, Salerno; 'L.S. and M.C.F. equally contributed to the work

\author{
Key Words \\ Directional migration $\bullet$ Ras $\bullet E R K \cdot$ Wound healing
}

\begin{abstract}
Background: Cell migration is essential in physiological and pathological processes, such as wound healing and metastasis formation. Ras involvement in these processes has been extensively demonstrated. This work attempts to characterize Ras regulation of the phenomena determining directional cell migration by separately analyzing the role of its principal effector pathways, MAPK and PI3K. Methods: NIH3T3 and NIHRasV12 fibroblasts were followed in wound healing assays to study, in time and under a directional stimulus, cell migration both under standard conditions and in presence of MAPK and PI3K inhibitors. Several parameters, descriptive of specific aspects of cell motion, were evaluated by coupling dynamic microscopy with quantitative and statistical methods. Quantitative Western Blots coupled with immunofluorescence stainings, were used to evaluate ERK activation. Results: Constitutive RasV12 activation confers to NIH3T3 the ability to close the wound faster. Neither increased cell proliferation nor higher speed explains the accelerated healing, but the increased directional migration drives the wound closure. Inhibition of ERK activation, which occurs immediately after wound, greatly blocks the directional migration, while inhibition of PI3K pathway reduces cell speed but does not prevent wound closure. Conclusion: Ras is greatly involved in determining and regulating directionality, ERK is its key effector for starting, driving and regulating directional movement.
\end{abstract}




\section{Cellular Physiology Cell Physiol Biochem 2013;31:123-142 \\ \begin{tabular}{ll|l} 
and Biochemistry & $\begin{array}{l}\text { DOI: 10.1159/000343355 } \\
\text { Publisnea onine: January 29, } 2013\end{array}$ & $\begin{array}{l}\text { C } 2013 \text { S. Karger AG, Basel } \\
\text { www.karger.com/cpb }\end{array}$ \\
\hline Sepe/Ferrari/Cantarella/Fioretti/Paolella: & Ras Activated Pathways Differentially Affect
\end{tabular} Directional Migration}

\section{Introduction}

Ras superfamily includes over one hundred small GTPases (20-25 kDa), involved in cellular signalling pathways responsible for controlling growth, migration, cell adhesion, cytoskeletal integrity, cell survival, differentiation and more [1, 2]. Ras family members are also known to be involved in almost all aspects of multi-step tumorigenesis [3]. It is estimated that at least one ras gene is oncogenically activated through somatic missense mutations in over $30 \%$ of human cancers [4]. In most cases these mutations result in amino acid changes at positions 12,13 and 61, causing impaired intrinsic GTPase activity and/ or conferring resistance to GAPs. As a result mutant Ras proteins accumulate in the active conformation, leading to constitutively activated pathways downstream from Ras, which are in turn responsible for the abnormal functional properties of cancer cells: uncontrolled cell growth, survival and differentiation, but also deregulated cell motility [5]. Motility is critical for tumor progression and dissemination, as metastasis formation implies the migration of tumour cells from the original location to distant sites.

Cellular systems expressing constitutively activated RasV12 [6-9], or dominant negative Ras (S17N) [10-13] have been used as in vitro models of cell motility. Progress in microscopy and image processing has been instrumental to quantitatively study the effect of different processes and events on cell migration. The observation of individual cells cultured in presence of chemotactic stimuli or of cell layers scratched by a wound has often been reported as means for studying directional movement [14]. Quantitative analysis of cell motility has been variously attempted by focusing on parameters describing average cell displacement, path linearity and direction followed during time. However, except for simple and intuitive measurements such as path length or speed, there is no general agreement on concepts like linearity or directionality, often treated by different authors in different way $[15,16]$.

By using these approaches, cell migration has been explored in an attempt to associate changes at the molecular level with morphological effects. The intracellular machinery responsible for cell motility is finely regulated at the molecular level to produce critical morphological events, such as cell polarization and changes of shape, triggered by cytoskeletal reorganization and eventually resulting in extension of protrusions and translocation of the cell body. Binding of Ras effectors to GTP-Ras is the starting molecular event triggering distinct signaling cascades that modulate cell behaviour [2]. Giving the growing number of these effectors, it is not surprising that the regulation of cell motility by Ras may involve many downstream pathways possibly cooperating with each other. The two main pathways, PI3K and MAPK, well known to play an important role in cell proliferation, differentiation and survival, have also been involved in regulating cell migration but their actions are still not perfectly clear. Active PI3K has been implicated in the regulation of actin polymerization and formation of lamellipodia at the leading edge of the migrating cells, through its activity on the GTP-binding Rac protein, a regulator of the actin cytoskeleton [17]. ERK pathway was implicated in the control of F-actin polymerization and focal adhesions turnover, required for cell morphogenesis and migration [18]. Further understanding of their specific role and/ or cooperation during cell motility is desirable.

The aim of this work was to study cell migration at molecular and quantitative level, by dissecting the role of Ras and its MAPK and PI3K effectors in regulating distinct features of cell migration, such as speed and directionality. In order to associate a specific aspect of cell migration to a precise effector, time-lapse microscopy and quantitative analysis were coupled to biochemical studies. The first approach consists of a combination of standard wound healing assays, time-lapse microscopy and a cell tracking system combined to tools for the quantitative evaluation of cell populations motility, i.e. the web application MotoCell, developed in our laboratory and previously described [19]. The association of this approach with the use of inhibitors allowed us to biochemically act on a specific Ras effector and quantitatively study the effect of this perturbation on distinct cell motion parameters. The 
Sepe/Ferrari/Cantarella/Fioretti/Paolella: Ras Activated Pathways Differentially Affect Directional Migration

results obtained demonstrate that directionality, more than speed, is associated with MAPK pathway and strictly depends on ERK phosphorylation.

\section{Materials and Methods}

\section{Materials}

PD 98059 (2'-Amino-3'-methoxyflavone) was purchased from Calbiochem. A stock solution (20 $\mathrm{mM}$ ) was prepared in DMSO, stored at $-20^{\circ} \mathrm{C}$ and used at final concentration of $40 \mu \mathrm{M}$. LY 294002 2-(4-Morpholinyl)-8-phenyl-4H-1-benzopyran-4-one) was purchased from Calbiochem. A stock solution $(10 \mathrm{mM})$ was prepared in DMSO, stored at $-20^{\circ} \mathrm{C}$ and used at final concentration of $10 \mu \mathrm{M}$.

\section{Cell lines: Culture and Propagation}

NIHRasV12 and NIHSrc527 were obtained by transfection of parental NIH3T3 fibroblasts with constitutively activated RasV12 (Glycine 12 to Valine) and Src527 (Tyrosine 527 to Phenylalanine) mutants, respectively. Murine fibroblasts with normal and transformed phenotype were grown in $100 \mathrm{~mm}$ diameter Petri plates, containing DMEM (Dulbecco's Modified Eagle's Medium) culture medium and 10\% FBS (fetal bovine serum). Penicillin $(10 \mathrm{U} / \mathrm{ml})$ and streptomycin $(10 \mathrm{ng} / \mathrm{ml})$ antibiotics and L-Glutamine $2 \mathrm{mM}$ were added to culture medium. Each operation was conducted in conditions of sterility under a laminar flow hood vertical. Cells were maintained in incubator at $37^{\circ} \mathrm{C}$ and with atmosphere made up to $95 \%$ air and $5 \% \mathrm{CO}_{2}$. The culture conditions and cell growth were followed by optical microscope observations. Cell propagation was performed by detaching cells with a solution of trypsin/EDTA (trypsin $0.05 \%$ and $0.53 \mathrm{mM}$ EDTA) and collecting them with complete culture medium. After centrifugation at $1200 \mathrm{rpm}$ for 10 minutes, pellets were suspended in fresh medium, properly diluted, and plated again. In order to plate cells with a specific density, the Burker chamber was used.

Time-Lapse Microscopy and Image Acquisition

Images from different samples have been acquired by using the Zeiss Cell Observer system. The system is composed by a motorized inverted microscope (Axiovert 200M), an incubator chamber for observation of living cells, and a digital camera (Axiocam H/R). The microscope is controlled by an Intel personal computer running Window XP through the Zeiss acquisition software (Axiovision 4.8.1) that manages the microscope and captures images both in bright field and fluorescence. The microscope is equipped with a halogen light for bright field observation and a LED illumination system for fluorescence. The instrument is also equipped with phase contrast optics and provides an incubator chamber to control the temperature (maintained at $37^{\circ} \mathrm{C}$ ) and the $\mathrm{CO}_{2}$ percent (maintained at $5 \%$ ) for the long observation of living cells. Within this work, digital frames were acquired as 16 bit images of 650x514 pixels.

\section{Random Motility Assay}

To investigate the random movement ability, cells were seeded (25000/well) in 12 well plates and maintained in complete medium at $37^{\circ} \mathrm{C}$ in an incubator with $5 \% \mathrm{CO}_{2}$. After 16-18 hours, the multiwell was placed in the incubator chamber of the microscope. The motility of cells was determined by recording phase contrast images (with an objective 10x), once every 10 minutes. The scale of the acquired images, obtained by recording a Burker chamber with known measures, was $0.767 \mathrm{pixel} / \mu$.

\section{Wound Healing Assay}

In order to study the dynamics of wound closure, cells were seeded in monolayers by plating in 12 well plates 100000 cells/well for NIH3T3 and NIHSrc527, and 200000 cells/well for NIHRasV12 in complete medium; 24 hours after plating the cell layer was scratched with sterile pipette tip. In order to perform the experiments in low serum, after 16-18 hours in complete medium, the cells were starved by using DMEM 0.5\% FBS for further 24 hours, than scratched. MEK inhibitor, PD $9805940 \mu \mathrm{M}$, or PI3K inhibitor, LY $29400210 \mu \mathrm{M}$, were used by pre-treating cells (or not, for the control samples) respectively for 1 hour or 30 minutes. The closure process was followed for 24 hours by acquiring one digital frame every 10 minutes with an objective $10 \mathrm{x}$ (scale $0.767 \mathrm{pixel} / \mu$ ). 
Quantitative analysis of wound invasion by cell populations located at the border was performed as follows. After wound injury, images were acquired at 2 hour intervals up to 24 hours (T0-T24h) and analyzed by measuring the area of the gap with ImageJ (National Institute of Health, USA). The average advancement of front cell populations was quantified by evaluating the ratio between the a-cellular area and the length of wound edge. For images containing the whole gap, the rate of empty space occupation was determined by calculating the ratio between the length at each time point $\left(\mathrm{Lt}_{\mathrm{i}}\right)$ and the length at start $\left(\mathrm{Lt}_{0}\right)$. Instead, if only one edge was comprised in the acquired image, the wound closure was expressed in terms of average edge advancement, obtained by evaluating at each time point the difference between initial $\left(\mathrm{Lt}_{0}\right)$ and current length $\left(\mathrm{Lt}_{\mathrm{i}}\right)$.

\section{Analysis of Single Cell Migration}

Tracking and quantitative analysis of individual migrating cells was done by using MotoCell, a web application developed in our laboratory [19]. Cell coordinates at each time step were obtained by manually tracking cell body location in successive frames. Quantitative analysis tools available in MotoCell were used to evaluate descriptive parameters, such as average speed and angle, directional persistence, path vector length, for the whole migrating cell population or combined by cell or step; within MotoCell, path length is defined as the sum of all subsequent steps made by a cell; speed as the average step length; linearity as the ratio of net cell displacement (i.e. the distance between the starting and end point) to path length.

Movement directionality was investigated in terms of the ability of a given cell to preferentially move in a single direction, close to an expected one, and of the whole cell population to migrate in a coordinate way, with directions concentrated around a reference one. Circular statistics analysis was used to evaluate the distribution of cell displacement directions [20]. The displacement vectors were combined without taking into account vector modules to obtain a resulting, having its origin in the centre of a circle with unit radius. Its direction is defined as the average angle, whereas its length is named linear dispersion coefficient $(\mathrm{R})$, which is descriptive of the dispersion of the angles around the average. $\mathrm{R}$ value ranges between 0 and 1: values close to 0 indicate a uniform angle distribution with no directional bias; larger values are obtained when displacement angles are clustered around a given direction, reaching 1 in the special case of all identical angles. The average direction of a population is the direction of the vector resulting by the composition of the displacement vectors obtained for each cell path.

The statistical significance of the observed directional bias, in relation to the number of experimental observations, was assessed by using the Rayleigh test [21], that compares the "null" hypothesis, i.e. a uniform distribution of cell displacement directions, against the alternative hypothesis of a non-uniform distribution, as for example in unimodal or other models, resulting in an asymmetric distribution of the displacement angles. The distribution of displacement angles was evaluated by fitting two distribution models to experimental data, the uniform circular and the von Mises, a unimodal circular distribution that fits well to points tightly concentrated around a given angle. When these analysis produced a preferential direction, this was compared to a reference angle to evaluate if and at what extent the observed directions are close to the reference one.

\section{Immunofluorescence}

Cells plated on coverslips were washed once with PBS 1x, fixed for 10 minutes at room temperature with paraformaldehyde ( $3 \% \mathrm{w} / \mathrm{v}$ in PBS), permeabilized for 5 minutes with Triton X-100 $(0.2 \% \mathrm{v} / \mathrm{v}$ in PBS) and incubated for 1 hour with PBS $1 x$ containing FBS (1\% v/v) to bind to any remaining sticky places. For ph-ERK1/2 detection, coverslips were stained by 1 hour incubation with mouse anti-phospho-p44/42 MAPK mAb (Cell Signaling Technology) 1:200 in PBS 1x and washed with PBS 1x. Coverslips were then incubated in texas red-conjugated goat anti-mouse antibody (Santa Cruz Biotechnology) 1:200 in PBS 1x. To visualize nuclei, coverslips were incubated for 10 minutes with PBS 1x containing Hoechst 33258 (Fluka) at a final concentration of $1 \mu \mathrm{g} / \mathrm{ml}$. The coverslips were mounted in Mowiol 4-88 (Calbiochem, CA) on glass slides. Slides were analyzed by using $40 \mathrm{x}$ oil objective.

\section{BrdU assay}

Proliferation rate was analyzed by BrdU incorporation assay. Cells were plated on coverslips and cultured up to $50 \%$ of confluence. Cells were then incubated with BrdU $100 \mu \mathrm{M}$ for 1 hour at $37^{\circ} \mathrm{C}$ and $5 \% \mathrm{CO}_{2}$. At the end of this incubation, coverslips were washed with PBS $1 \mathrm{x}$, fixed for 10 minutes at room 
temperature with paraformaldehyde 3\%, permeabilized for 5 minutes with Triton X-100 $0.2 \%$ and incubated for 10 minutes with $\mathrm{HCl}$ (1.5 M in PBS $1 \mathrm{x})$. After, coverslips were washed and incubated with diluted (1:10 in PBS 1x) primary antibody, mouse anti-BrdU mAb (clone BU-33 from Sigma), then treated with diluted (1:200 in PBS 1x) secondary antibody, texas red-conjugated goat anti-mouse (Santa Cruz Biotechnology). To visualize nuclei, coverslips were incubated for 10 minutes with PBS 1x containing Hoechst 33258 (Fluka) and finally washed three times with PBS 1x. The coverslips were mounted in Mowiol 4-88 (Calbiochem, CA) on glass slides and analyzed by using 40x oil objective.

\section{Lysate preparation and Immunoblotting}

NIH3T3 cells were washed twice with cold PBS 1x, directly solubilized in denaturing sample buffer (Tris/HCl 50 mM pH 7.0, NP-40 0,5\%, NaCl 250 mM, NaOV 10 mM, NaF 25 mM, NaPP 20 mM, 1 protease inhibitor cocktail tablet in $10 \mathrm{ml}$ of extraction solution). Protein samples (20 $\mu \mathrm{g}$ ) were supplemented with $5 \%$ Dye buffer $5 \mathrm{x}$ and denaturated by boiling at $90^{\circ} \mathrm{C}$. Polyacrylamide gels were used at $10 \%$ of acrylamide concentration. The proteins were transferred to the nitrocellulose membrane, stained with a $0.2 \%$ Ponceau S red solution to check the transfer efficiency and subsequently washed with distilled water. The nitrocellulose membrane was saturated with 5\% non-fat dry milk in TBS solution (TBST), at room temperature for 1 hour. The membrane was washed twice with TBST solution, then incubated overnight at $4^{\circ} \mathrm{C}$ with the primary antibody. For ph-ERK1/2 detection was used a mouse anti-phospho-p44/42 MAPK mAb (Cell Signaling Technology), 1:2000 in milk. For beta-tubulin detection, a rabbit anti-beta tubulin mAb (Cell Signaling Technology) was used 1:2000 in milk. The membrane was washed with TBST solution before to be incubated for 1 hour at room temperature with the secondary antibody. Anti-rabbit IgG coupled to the horseradish peroxidase (Amersham Biosciences) was used 1:3000 in milk; anti-mouse IgG coupled to the horseradish peroxidase (Amersham Biosciences) was used 1:2000 in milk. The membrane was then washed and the detection of proteins was done with Immobilion Western HRP chemiluminescent substrate (Millipore). Digital images were acquired with a Bio-Rad imaging instrument, ChemiDoc XRS-system, and quantitatively evaluated.

\section{Results}

Speed and Proliferation Rate do not Fully Explain Accelerated Wound Closure by RasV12 Fibroblasts

The effect of constitutive Ras activation in NIH3T3 fibroblasts was tested by following the wound healing process in time-lapse (Fig. 1A). Fibroblasts overexpressing the constitutively active RasV12 variant (NIHRasV12) move quickly and fully repair the wound within the 24 hours period of observation, unlike the parental NIH3T3 cells, which move towards the gap, but fail to completely close the gap within the same time period. By observing the movies the two cell lines appear to invade the empty space by using a different migratory strategy (Fig. 1B). Immediately after the wound, both cell types become polarized and start to extend filopodial and lamellipodial protrusions at the leading edge, but while NIHRasV12 cells (white circle) quickly move towards the wound as isolated individual cells, parental NIH3T3 cells (black circle) appear to move in a slower, more coordinated way, almost as if in a sheetlike structure.

Filling the empty space to close the wound is favoured by at least two factors: cell proliferation and migration, both known to be positively regulated by Ras. In order to assess their relative contribution, NIH3T3 fibroblasts expressing a different mutated oncogene, Src527, similarly able to induce transformation and increased proliferation rate, were observed after subjecting them to the wound stimulus. As shown in Fig. 2A, NIHSrc527 fail to close the wound within the $24 \mathrm{~h}$ observation time, although their proliferation rate $(52 \%$ cells positive for BrdU incorporation) is similar to NIHRasV12 (56\%) and clearly higher than that of NIH3T3 cells (30\%), as reported in Fig. 2B.

Quantitative analysis of random motility shows that average speed of NIHRasV12 (16.5 $\mu \mathrm{m} / 40 \mathrm{~min}$ ) is much higher than both NIH3T3 (6.4 $\mu \mathrm{m} / 40 \mathrm{~min})$ and Src527 transformed fibroblasts $(7 \mu \mathrm{m} / 40 \mathrm{~min})$, as reported in Fig. $2 \mathrm{C}$. To assess whether this speed difference is 
Fig. 1. Wound healing assay with parental and RasV12 transformed NIH3T3 fibroblasts. A) Timelapse acquisition of NIH3T3 and NIHRasV12 cells immediately after the wound $\left(\mathrm{T}_{0}\right)$, and after 12 and 24 hours $\left(\mathrm{T}_{12 \mathrm{~h}}\right.$ and $\left.\mathrm{T}_{24 \mathrm{~h}}\right)$. B) Enlarged detail of NIH3T3 and NIHRasV12 entering the open space left by the wound: NIHRasV12 cells move towards the wound as isolated individual cells, while parental NIH3T3 cells move in a more coordinated way, similar to a sheetlike structure.

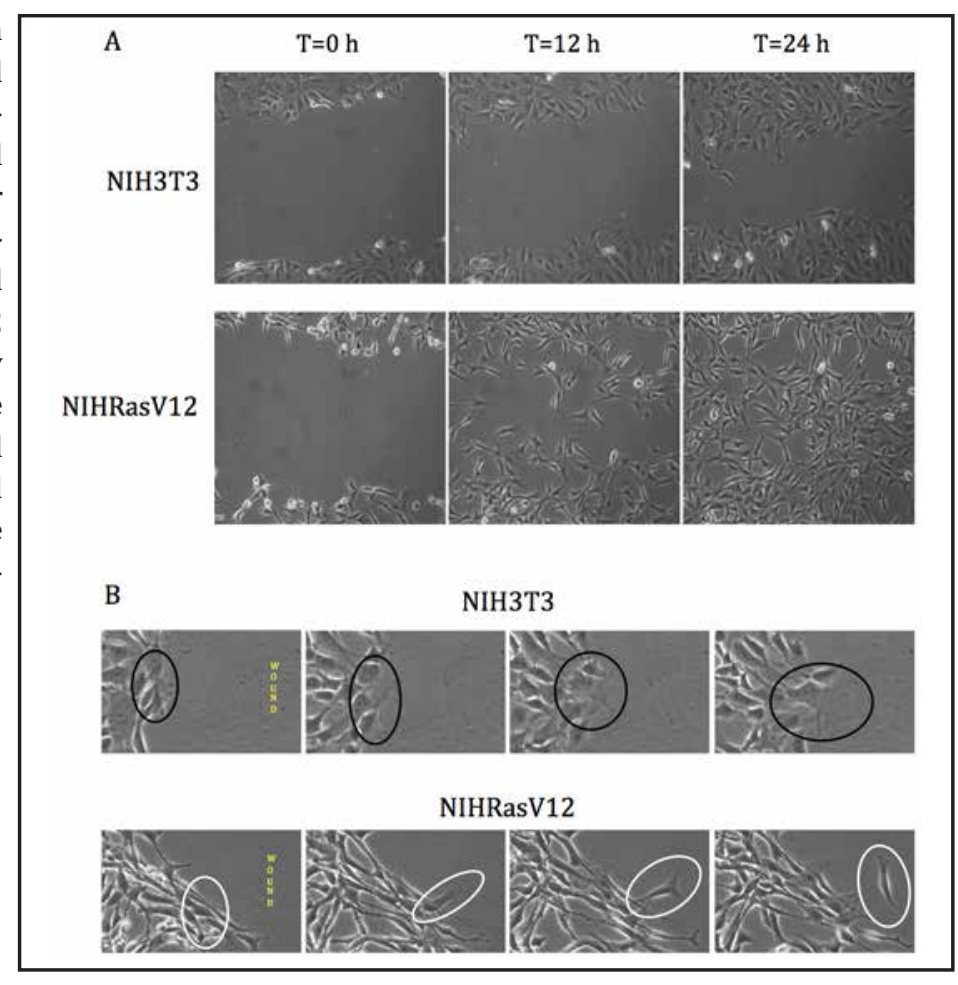

Fig. 2. Effect of increased proliferation and speed on wound closure. A) Wound healing assay for NIHRasV12 and NIHSrc527 cells: frames at start $\left(\mathrm{T}_{0}\right)$ and end $\left(\mathrm{T}_{24 \mathrm{~h}}\right)$ extracted from time-lapse acquisi-tions. B) BrdU incorporation rates and C) average speed of migration for NIH3T3, NIHRasV12 and NIHSrc527 fibroblasts randomly plated. D) Average speed values under low serum culture conditions $(0,5 \%$ serum), for NIH3T3 and NIHRasV12 cells compared with those observed under standard

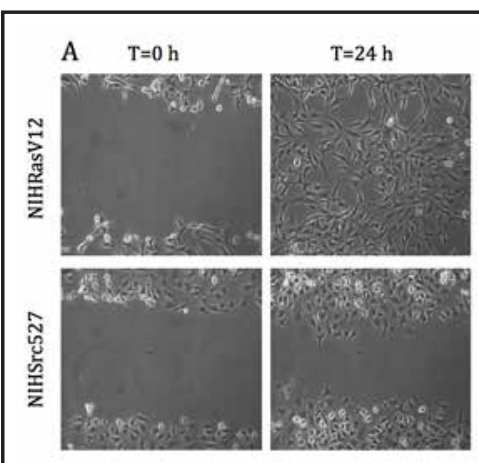

B

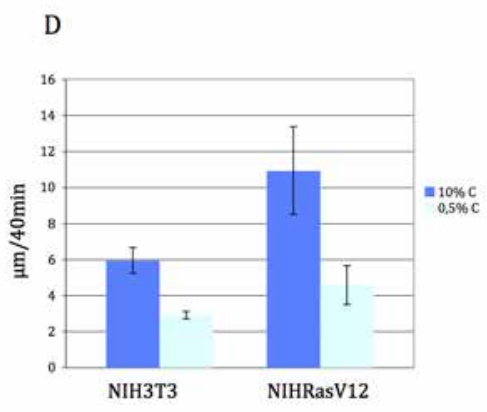

conditions (10\% serum). E) Wound healing assay under low serum culture conditions, for NIHRasV12 and NIH3T3 cells: frames at the beginning $\left(\mathrm{T}_{0}\right)$ and the end $\left(\mathrm{T}_{24 \mathrm{~h}}\right)$ of a 24-hour time-lapse acquisition.

an advantage towards accelerating wound closure, the above experiments were repeated in $0.5 \%$ serum, a limiting growth condition where a strong speed reduction is expected [22]. The results, reported in Fig. 2D, show that under these conditions, NIHRasV12 cells move at $5 \mu \mathrm{m} / 40 \mathrm{~min}$, a pace even lower than the $6 \mu \mathrm{m} / 40 \mathrm{~min}$ seen for NIH3T3 and NIHSrc527 in 
Sepe/Ferrari/Cantarella/Fioretti/Paolella: Ras Activated Pathways Differentially Affect Directional Migration

Fig. 3. Characteristics of movement during random migration and wound healing. A) Linearity values obtained during random migration (left), for NIH3T3 and NIHRasV12 cells, compared with those observed in wound healing assay (right). B) Polar plots representing the distribution of directions for NIH3T3 and NIHRasV12 populations moving random (left) are compared with those obtained for both populations wounded (right). C) Linear dispersion values $\mathrm{R}$, for both NIH3T3 and NIHRasV12 fibroblasts in random movement assay (left) or under wound stimulus (right), are indicated together with the significance levels, for $\mathrm{P}<0,01$, reported as transparent grey boxes overlaid onto the histogram. D) Average angle

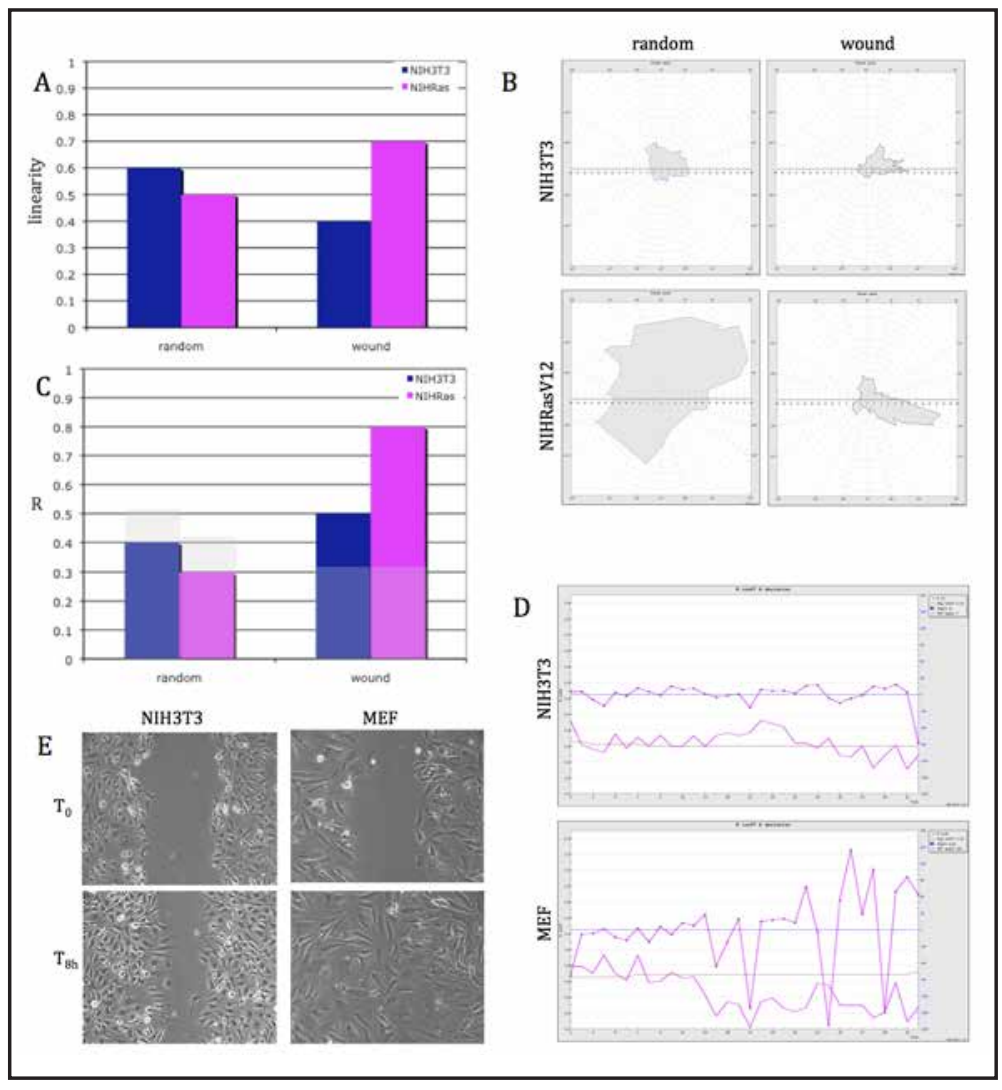

values (top curve respect to the right $\mathrm{Y}$ axis) and linear dispersion $\mathrm{R}$ values (bottom curve, scale on the left vertical axis) are plotted against time for NIH3T3 (upper chart) and MEF (lower) cells. The lower dotted lines indicate the threshold level for $\mathrm{P}<0.01$. E) Frames at start $\left(\mathrm{T}_{0}\right)$, and 8 hours after wound injury $\left(\mathrm{T}_{8 \mathrm{~h}}\right)$, when MEF close the gap, were extracted from 24 hours time-lapse acquisition for both NIH3T3 and MEF fibroblasts.

$10 \%$ serum (Fig. 2C), but they are still able to invade within 24 hours the space left open by the wound, in a more effective way than NIH3T3 cells not only in $10 \%$ serum (Fig. 1A), but also in $0,5 \%$ (Fig. 2E).

\section{Directional Migration Induced by RasV12 is the Main Factor Behind Accelerated Wound Healing}

Beyond speed, the features of cell migration may be described by additional parameters, such as path linearity and directional bias. To assess whether constitutive Ras activation is able to affect these parameters, they were analyzed in both random conditions, i.e. in absence of stimulus, and under wound stimulus, for NIH3T3 and NIHRasV12 cells. Within this work, linearity is defined as the ratio between the module of a vector describing the net cell displacement (i.e. the distance between the start and end point of the path), and the length of the full path followed by the cell (see also under "Materials and methods"). As shown in Fig. $3 \mathrm{~A}$, for randomly moving cells linearity values remain around 0.5 or a little above that, and are similar for NIH3T3 and NIHRasV12 fibroblasts, but in the course of wound healing experiments, for fibroblasts with constitutive Ras activation, values become substantially higher (reaching 0.7), indicative of a straight path.

In Fig. 3B, each polar plots represents the profile generated by connecting the ends of the various cell displacement vectors, reported as starting from the origin of the axes, after smoothing. The plots on the left were obtained for random moving cells, where the 
uniform distribution of directions is easily recognized by the circular shape of the area, for both NIH3T3 and NIHRasV12 cells. The size of the area depends on the length of the net displacement, higher for the faster NIHRasV12 than for NIH3T3 cells. The shape of the plots indicates the predominant direction of cells displacements: both cell lines, when subjected to a wound, respond by turning to directional migration and move into the empty space by following paths predominantly oriented towards the centre of the wound, as indicated in the panels on the right, where the areas have a typical asymmetrical shape. The effect is much more evident for NIHRasV12 cells.

The directional component of cell movement was quantitatively assessed by using circular statistics analysis (described under "Materials and methods"). With this assay, linear dispersion (R) values close to 0 are indicative of unbiased distribution of the steps, whereas higher values, up to 1.0, indicate a progressively increasing degree of the directional component. Statistical significance of directional bias was evaluated by testing the "null" hypothesis of uniform distribution of cell displacements, against the alternative hypothesis of non-uniform distribution of directions, as for example in unimodal or other patterns, anyway leading to an asymmetric distribution of the directional angles [20]. The procedure described by Rayleigh [21] was used to test for significance, where $\mathrm{R}$ values are compared to a threshold level, corresponding to the highest $\mathrm{R}$ value expected from a random distribution, for a given probability $(\mathrm{P}<0.01)$ and number of samples. The results reported in Figure 3C show, for the two randomly moving cell populations, linear dispersion values ranging between 0.3 and 0.4 , both lower than their respective threshold values for $\mathrm{P}<0.01$ represented by transparent grey boxes, overlaid onto the histogram. For cells moving in wound healing assays, the same analysis shows a clear directional bias, much stronger for NIHRasV12 (0.8) than for NIH3T3 (0.5). In both cases, R values are higher than the threshold for $\mathrm{P}<0.01$.

The data shown until now demonstrate that cell attitude to coordinately move in a directional way is strongly enhanced following the wound stimulus. The statistical parameters were calculated by combining the steps moved by all tested cells during the whole observation period. However, as the healing process takes time to happen, directionality parameters were also calculated for the whole cell population at each step, to evaluate whether cells preferentially move in a given direction and if they maintain it during time. In Fig. 3D, R and average angle are plotted against time for both NIH3T3 and another mouse embryo fibroblast cell line (MEF). For NIH3T3 cells, R values (bottom curve, scale on the left vertical axis) are consistently high and often above the threshold level for $\mathrm{P}<0.01$ (lower dotted line). Angular deviations (top curve, right $\mathrm{Y}$ axis in the same graph) are very low, indicating that directions remain very close to the reference direction, i.e. towards the centre of the wound. Taken together, these data indicate that NIH3T3 cells constantly maintain the same direction during the whole 24 hours observation time. Similarly MEF fibroblasts show $R$ values and deviations consistent with strongly unidirectional movement for the first 12 steps (about 8 hours after the layer injury); in the subsequent steps, R values become lower and well below the reference threshold, while angles are scattered in all directions. These results support the idea that directional movement strictly depends on the presence of the wound, as it remains clearly visible until the gap stays open and disappears soon after wound closure, as shown in Fig. 3E, where MEF cells completely fill the gap within approximately 8 hours, unlike NIH3T3 that leave it nearly empty for most of the 24 hours (see also Fig. 1A).

Wound repair involves cells in a different way: when three cell sub-sets, respectively named front, middle and inner (Fig. 4A), are defined according to distance from the wound edge, the behaviour of each subset may be observed and separately analyzed. The paths followed by each subpopulation are reported as single cell paths in Fig. 4B and in aggregated form in Fig. 4C: the front population always appears to be more strongly directed towards the wound than the others for both NIH3T3 and NIHRas cells. Circular statistics analysis (Fig. 4D and F) shows that the wound edge has a clear effect on migration of both NIH3T3 and NIHRasV12 cells, i.e. the observed motion is strongly directional, with high $\mathrm{R}$ values (respectively 0.5 and 0.8 , close to or well above the threshold for $\mathrm{P}<0.01$ ). For RasV12 


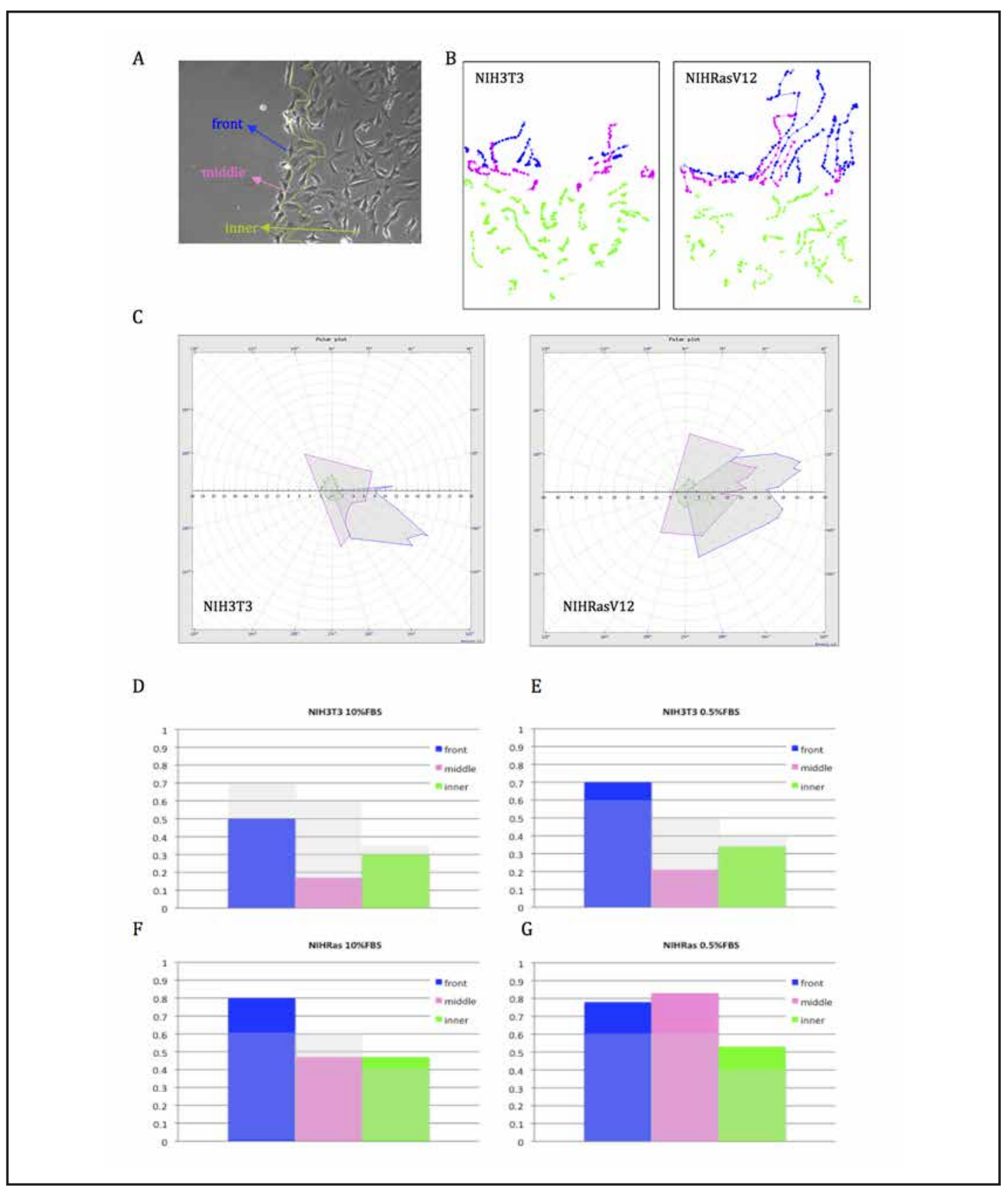

Fig. 4. Identification and analysis of subpopulations. A) Front, middle and inner cell subpopulations, separated according to their distance from the wound. Typical paths followed by NIH3T3 and NIHRasV12 cells during wound healing under standard culture conditions are reported in B): the sub-populations, indicated in blue for the front, magenta for the middle and green for the inner population, have been placed with the empty space on the upper side. C) Polar plots describing NIH3T3 (left) and NIHRasV12 (right) subpopulations: the wound is on the right. D) and E) R coefficient values for each NIH3T3 subpopulation in wound healing assays, respectively in 10\% and 0,5\% serum. F) and G) The same data as in C) and D), but for NIHRasV12 fibroblasts.

transformed cells, movement remains directional also in the two other subpopulations, unlike NIH3T3 cells which move in a much less directional way. When the same experiment is repeated in 0,5\% serum, where, as shown in Fig. 2D, limiting conditions result in reduced speed, directionality is not affected: for NIH3T3 (Fig. 4E) only cells surrounding the wounds 


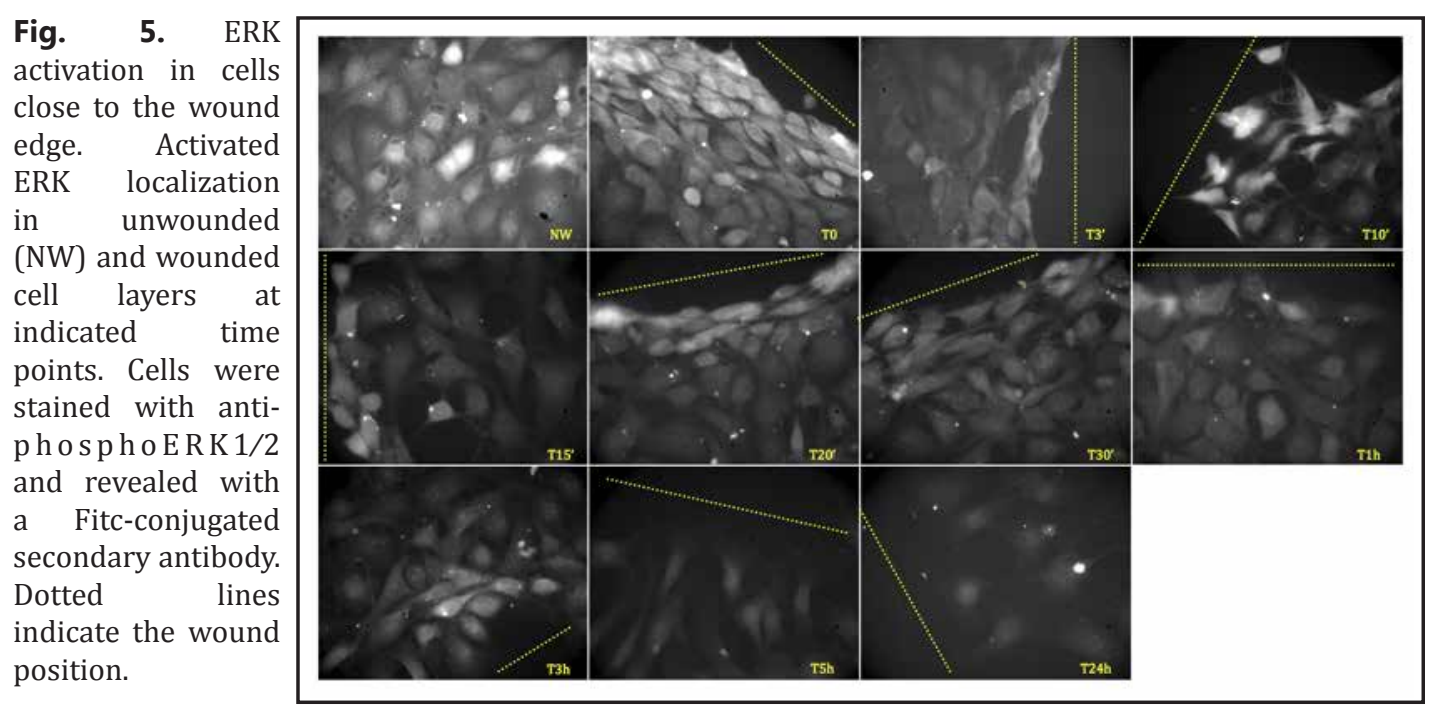

move in a clearly directional way, while, all subpopulations of RasV12 (Fig. 4G) show a clear directional bias $(\mathrm{P}<0.01)$, with $\mathrm{R}$ values even higher than in standard $10 \%$ serum.

\section{ERK is Rapidly Activated and Plays an Important Role In Wound Closure}

To elucidate the biochemical phenomena involved in regulating the described migratory behaviour, ERK activation after a wound was evaluated in fibroblast monolayers by both immunofluorescence and Western Blot. Activated ERK is, in fact, known to be increased in migrating epithelial cells in the course of wound healing [23].

In Fig. 5, activated ERK was analyzed in NIH3T3 fibroblasts, by in situ immunofluorescence by using the anti-phospho-ERK1/2 antibody, in unwounded (NW) and wounded cells, at different time points after the wound. ERK phosphorylation is increased immediately after the wound and remains high up for about 20 minutes (T3'-T20'), preferentially in cells located close to the edge. After that, the signal gradually becomes more diffuse. After 3-5 hours, a second ERK activation phase is often observed (T3h-T5h) especially in cells showing the typical 'migratory' appearance, characterized by elongated cell shape and nucleus retraction. The signal returns to the basal level within 24 hours (T24h).

ERK activation was quantitatively evaluated by Western Blot analysis. As ERK appears to be preferentially activated at the wound edge, where cells showing a stronger directional behaviour are located, a protocol was developed to obtain a population strongly enriched in such cells, by introducing a large number of parallel wounds. Briefly, confluent NIH3T3 monolayers were repeatedly wounded with a tool able to create a number of parallel wounds, separated by narrow stripes of monolayer cells (about $1 \mathrm{~mm}$ wide). Western blots were then stained for phosphorylated ERK by using the anti-phospho-ERK1/2 antibody. In Fig. 6A, phosphorylation patterns are reported at various times up to 24 hours after wounding, quantitative assessment is reported in Fig. 6G (dark curve). Two peaks of ERK phosphorylation are visible: the first appears immediately after the wound $\left(\mathrm{T}_{0}\right)$, reaches its maximum around 3 minutes and is already going down 10 minutes after the stimulus, to return to values well below the basal level, i.e. that of unwounded cells, after one hour. Later on, there is a second, less intense, but longer, activation phase, characterized by a phosphoERK peak around 3-5 hours. These two phases, corresponding to a transient and strong early peak, followed by a lower and sustained raise, appear to replicate the previously described ERK activation patterns, observed by immunofluorescence in monolayer cells. Total amount of ERK1/2 remains unmodified, thus confirming that differences in phosphorylated ERK should be ascribed to phosphorylation changes rather than variation in amount of the proteins during the 24 hours. Similar results were obtained for NIHRasV12 fibroblasts, as shown in Fig. 6B and 6H (dark curve). 


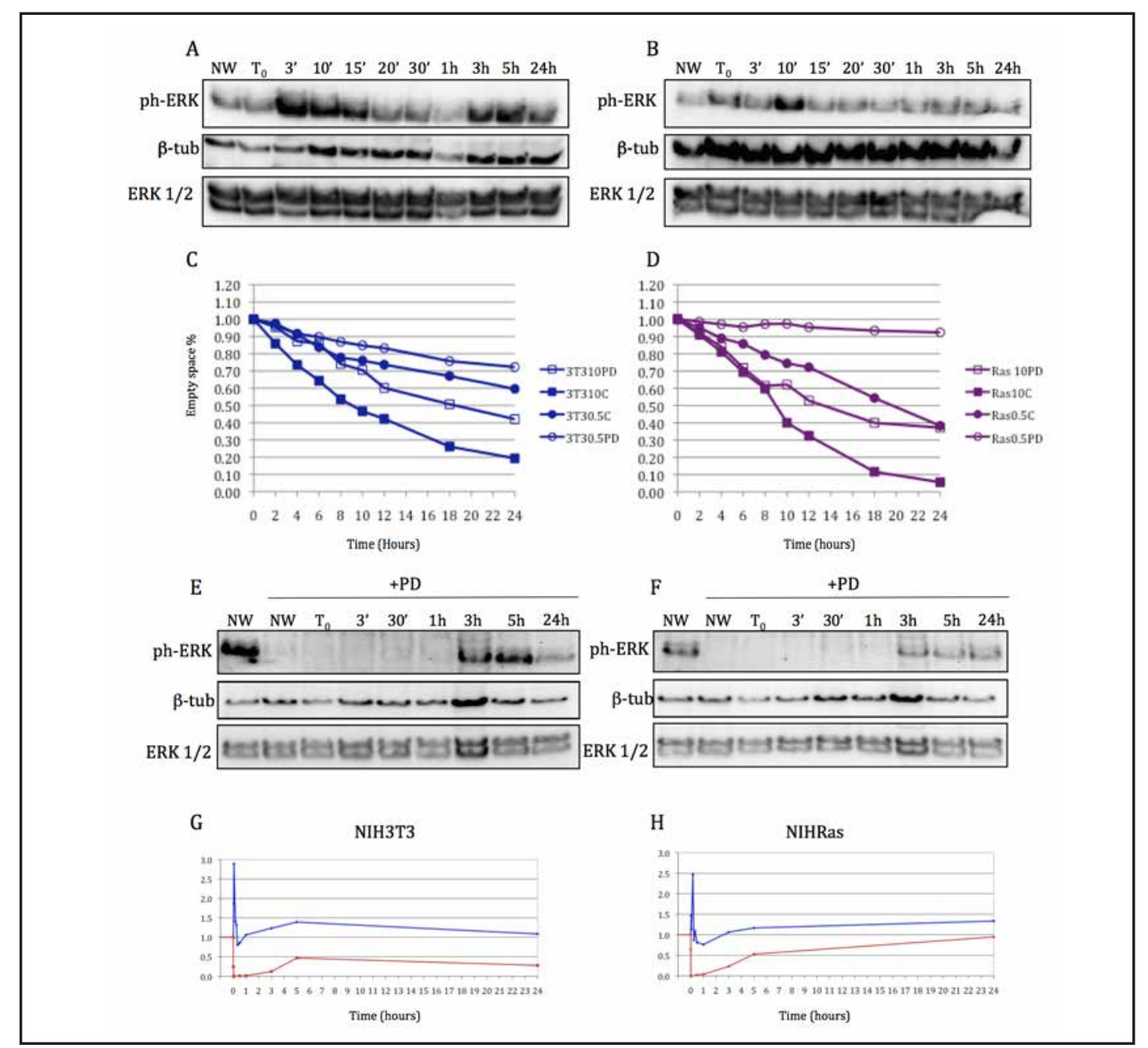

Fig. 6. ERK activation and wound healing assays in presence of PD 98059. Western blot analysis of protein extracts from populations highly enriched for cells close to the wound (see Methods) is reported for NIH3T3 in A) and for NIHRasV12 in B). The rate of occupation of empty space evaluated as the ratio between the length at each time points ( $\mathrm{Lt}_{\mathrm{i}}$ ) and the length at start $\left(\mathrm{Lt}_{0}\right)$ is reported in $\mathrm{C}$ ) for NIH3T3 and D) for NIHRasV12 fibroblasts, at time points corresponding to snapshots taken at 2 hour intervals up to 24 hours after the wound, under both standard (10\%, squares) and limiting $(0.5 \%$, circles) serum condition. E) Western blot of ph-ERK1/2, beta-tubulin and ERK1/2 from wounded confluent monolayers of NIH3T3 fibroblasts pretreated for 1 hour with PD 98059; F) same as in E) for NIHRasV12. G) ph-ERK1/2 levels plotted as a function of time for control NIH3T3 (upper curve) and pretreated for 1 hour with PD 98059 (lower curve). H) same as in G) for NIHRasV12 fibroblasts.

The role played by ERK on wound healing, was analyzed by using PD 98059, an inhibitor known to block MEK activity and, consequently, ERK phosphorylation and activation. Timelapse movies were analyzed by evaluating the rate of acellular space occupation by cells located at its edges. The results are reported in Fig. 6C for NIH3T3 and 6D for NIHRasV12 cells, at time points corresponding to snapshots taken at 2 hour intervals up to 24 hours after the wound $\left(\mathrm{T}_{0}-\mathrm{T}_{24 \mathrm{~h}}\right)$. Addition of PD 98059 always results in reduced edge progression, as indicated by the curves depicted by the open symbols, consistently running below the corresponding curves for untreated cells (closed symbols), under both standard $(10 \%$, squares) and limiting (0.5\%, circles) serum condition. Inhibition by PD 98059 was assessed 


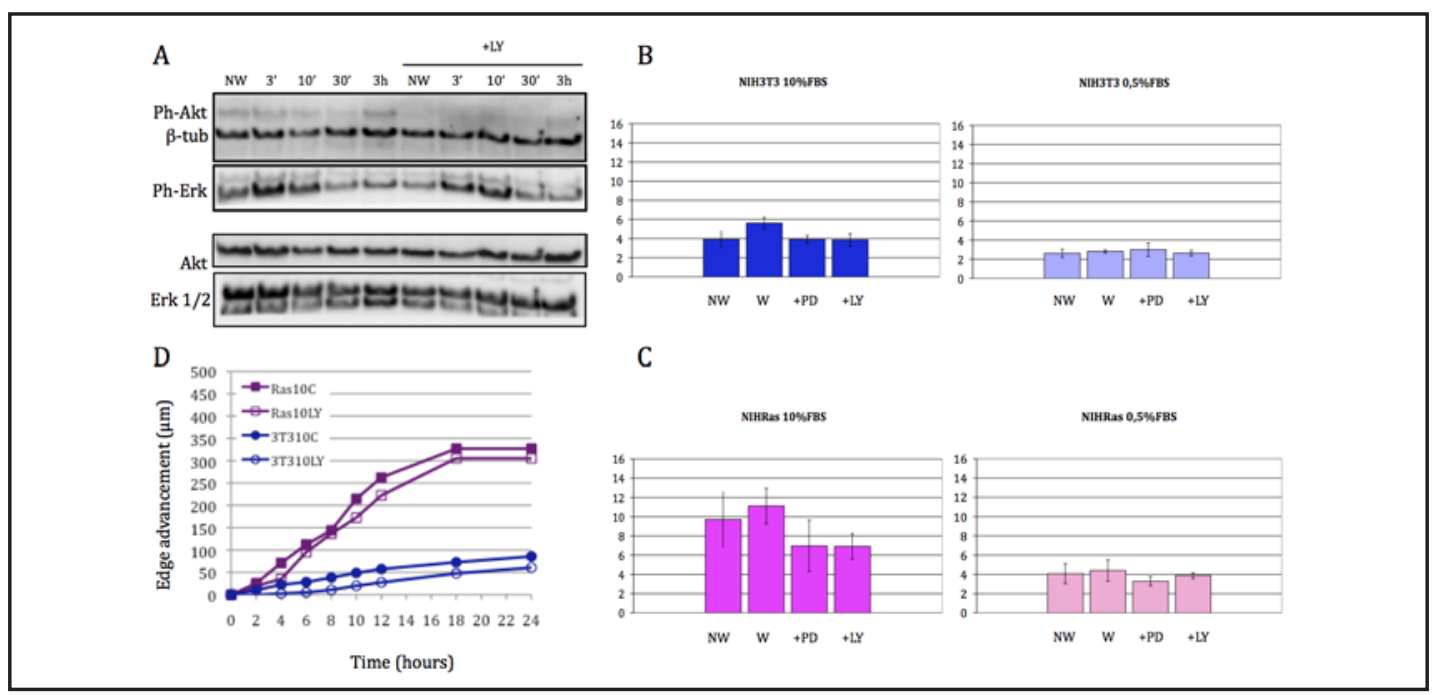

Fig. 7. Migration of NIH3T3 and NIHRasV12 fibroblasts in presence of PD 98059 and LY 294002. A) Western blot of ph-AKT, AKT and beta-tubulin together with ph-ERK and ERK1/2 from wounded confluent monolayers of NIH3T3 fibroblasts pretreated for 1 hour with LY 294002. B) Average speed for NIH3T3 in $10 \%$ (left) and in 0,5\% serum (right), under the following conditions: no wound (NW), wound (W), wound in presence of PD 98059 (+PD), wound in presence of LY 294002 (+LY). C) Same as in B) for NIHRasV12 cells. D) Wound closure in presence of LY 294002, expressed as edge advancement in time (see Methods). The results are reported at 2 hour intervals up to 24 hours after the wound, for NIH3T3 (circles) and NIHRasV12 (squares) fibroblasts. Open symbols report data obtained in presence of LY 294002, while the closed ones indicate results obtained in absence of it.

by testing phosphorylated ERK in monolayers of NIH3T3 (Fig. 6E and G) and NIHRasV12 (Fig. 6F and H) fibroblasts, pre-treated for 1 hour with the inhibitor before the wound. For both cell lines, PD 98059 completely inhibits both activation peaks (light curve) observed in absence of the inhibitor (dark curve). The amount of total ERK1/2 is not affected. The small recovery observed at about 5 hours is not different from that observed in unwounded monolayer cells in PD 98059 stability tests, where inhibitory activity, starts to decay a few hours after PD 98059 addition, although remaining clearly detectable up to 24 hours, with ph-ERK levels well below controls (data not shown).

In addition to evaluating the effect of Ras activation on ERK, the role of the PI3Kinase pathway in responding to the wound stimulus was also investigated, by using LY 294002, an inhibitor of PI3K activity. In Fig. 7A, ph-AKT levels were assayed in NIH3T3 fibroblasts, by using an anti-ph-Thr308AKT antibody in western blot analysis. A basal amount of activated AKT (NW) is observed in unwounded cells that remains essentially the same after the wound stimulus. In presence of LY 294002, ph-Thr308AKT signal is low or even absent. The ph-ERK signal, as might be expected, in these experiments follows the same pattern as under control conditions. Under both conditions, the amount of total AKT is not affected.

MAPK and PI3K Differently Affect Cell Migration: MAPK, but not PI3K Inhibition Blocks Directional Movement

Wound healing assays were performed by quantitatively analysing distinct features of movement, such as speed and directionality of migrating cells, in presence of PD 98059, as well as in presence of LY 294002. The effect of the two inhibitors on the speed component of cell migration are reported in Fig. 7, where wounded (W) NIH3T3 and NIHRasV12 cell populations (7B and C, left panels) are shown to move at higher speed (5.60 and 11.12 $\mu \mathrm{m} / 40 \mathrm{~min}$ ) than cells in unwounded monolayers (NW, 3.91 and $9.70 \mu \mathrm{m} / 40 \mathrm{~min}$ ). PD 98059 addition (+PD) affects speed of both cell lines: in NIH3T3 fibroblasts speed is reduced to levels similar to the unstimulated culture, while NIHRasV12 cells suffer stronger speed 
Sepe/Ferrari/Cantarella/Fioretti/Paolella: Ras Activated Pathways Differentially Affect Directional Migration

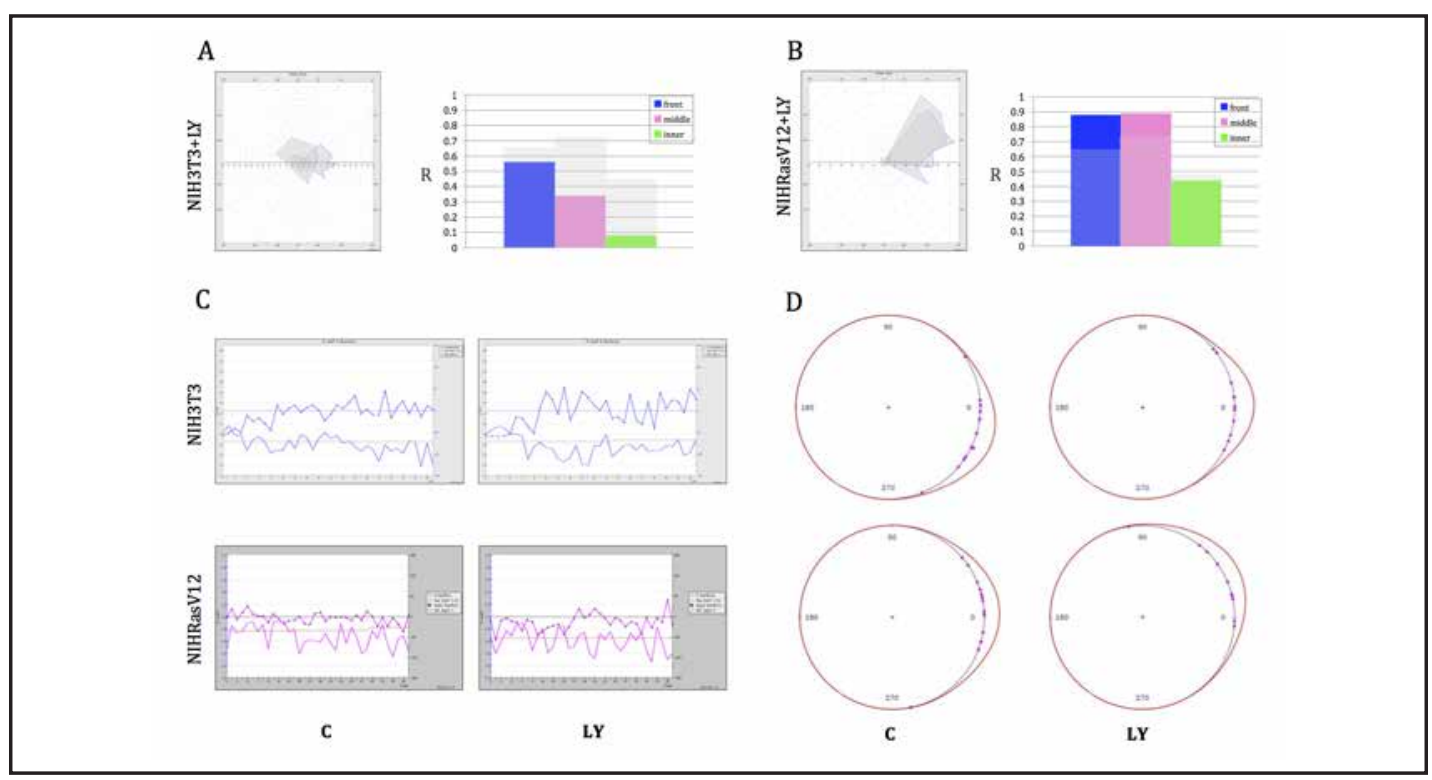

Fig. 8. Analysis of NIH3T3 and NIHRasV12 directional migration in presence of LY 294002. A) Net displacements (left) and R coefficient (right), for each NIH3T3 subpopulation. B) Same as in A) for NIHRasV12 cells. C) Linear dispersion (R) and average angle plotted vs time for the sole external subpopulation of NIH3T3 (upper) and NIHRasV12 (lower) cells, cultured in absence (C) or in presence (LY) of LY 294002. The dotted lines represent the expected direction and the Rayleigh coefficient for $\mathrm{P}<0.01$, respectively. D) Cell path directions (dots) and curve depicting the best fit of a von Mises distribution to them (line) plotted around a unit circle. For both NIH3T3 and NIHRasV12 cells, the analysis was carried out under control conditions (C) and in presence of LY 294002 (LY). In all these analysis the wound was on the right.

reduction, producing values $(6.96 \mu \mathrm{m} / 40 \mathrm{~min})$ well below those of the unstimulated culture, possibly because of constitutive Ras pathway activation in these cells. Inhibition of the other Ras signalling path by PI3K inhibitor LY 294002, also reduces the speed of both fibroblasts (+LY, for NIH3T3 $3.85 \mu \mathrm{m} / 40 \mathrm{~min}$ and for NIHRasV12 $6.90 \mu \mathrm{m} / 40 \mathrm{~min}$ ) and this drop is very similar to that observed in presence of ERK activation inhibitor. Under low serum conditions (Fig.7B and C, panels on the right), no effect on speed is seen by both inhibitors, however it should be taken into account that speed of untreated controls is by itself low (see Fig. 2D). In spite of the similar speed reduction, PD 98059 and LY 294002 differently affect wound closure, with the second completely unable to alter linear progression of the wound edge, as reported in Fig.7D. For both NIH3T3 (circles) and NIHRasV12 (squares) fibroblasts, during the whole observation period, the curves representing edge advancement in presence of LY 294002 (open symbols) run very close to the curves for untreated cells (closed symbols).

Analysis of directional movement highlights the different behaviour of cells cultured in presence of LY 294002 and PD 98059 inhibitors. When cell displacements are represented in polar plots (Fig. 8A and B, left panels), the directional bias is still clearly visible in LY 294002 treated cells. Linear dispersion values (R), shown on the right side of Fig. 8A for NIH3T3, and 8B for NIHRasV12, are high and comparable to those measured in absence of the inhibitor (see Fig. 4B and C) for both lines. In Fig. 8C, linear dispersion coefficient and average angle are plotted vs time step, for the sole external subpopulation: LY 294002-treated cells maintain high $\mathrm{R}$ values for most of the observation time (panels on the right, LY), well above the threshold level for $\mathrm{P}<0.01$ (lower dotted line), a behaviour similar to that of untreated cells (panels on the left, bottom curve). The average angle, reported in the same graph as deviation from the direction pointing towards the wound, confirms that the directional bias is not lost for cells growing in presence of LY 294002: as for untreated cells, the average angle remains centered, within a few degrees of the expected one, for most of the observation 
Sepe/Ferrari/Cantarella/Fioretti/Paolella: Ras Activated Pathways Differentially Affect Directional Migration

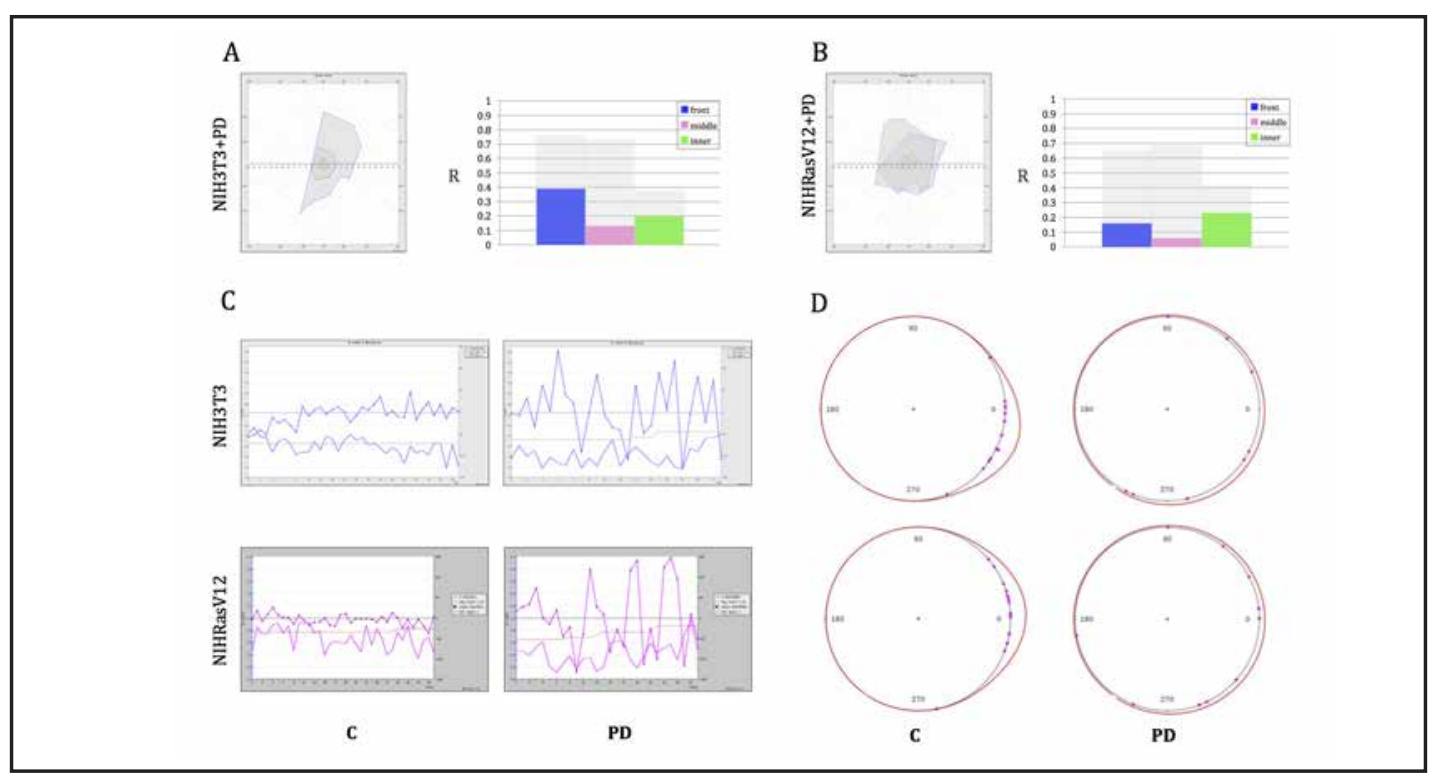

Fig. 9. Analysis of NIH3T3 and NIHRasV12 directional migration in presence of PD 98059. A) Net displacements (left) and R coefficient (right), for each NIH3T3 subpopulation. B) Same as in A) for NIHRasV12 cells. C) Linear dispersion (R) and average angle plotted vs time for the sole external subpopulation of NIH3T3 (upper) and NIHRasV12 (lower) cells, cultured in absence (C) or in presence (PD) of PD 98059. The dotted lines represent the expected direction and the Rayleigh coefficient for $\mathrm{P}<0.01$, respectively. D) Cell path directions (dots) and curve depicting the best fit of a von Mises distribution to them (line) plotted around a unit circle. For both NIH3T3 and NIHRasV12 cells, the analysis was carried out under control conditions (C) and in presence of PD 98059 (PD). In all these analysis the wound was on the right.

time. Directional bias is lost, in contrast, in presence of PD 98059 inhibitor (Fig. 9). The result is already visible in polar plots, where cell displacements are randomly distributed and form a circle around the origin (Fig. 9A and B, left panels). Consistently, low R values are observed in all cell populations. Similarly, for NIH3T3, a clear reduction may be seen in cells located closest to the wound (Fig. 9A and B, right panels), i.e. the only subpopulation with high $\mathrm{R}$ values in absence of inhibitor (Fig. 4C). This reduction is even more dramatic for NIHRasV12 cells, where R values are also strongly reduced in all subpopulations, with the front one dropping to 0.15 from around 0.8 observed in absence of inhibitor (see Fig. 4E). In Fig. 9C, R and average angle have been analysed for the front subpopulations during the whole 24 hour observation time. For PD 98059-treated normal and transformed cell lines, the subpopulations surrounding the wound feature R values (bottom line) much lower then in untreated cells (panels on the left) and show no indication of directional migration. The loss of directional bias is associated with loss of directional consistency: in fact, as shown in the panels on the right (upper line), directions are scattered along the whole $-180^{\circ}$ to $+180^{\circ}$ range, very often far from the reference angle.

The distribution of direction angles was also evaluated by using the von Mises distribution function, a unimodal circular distribution that fits well to points tightly concentrated around a given angle [24], to model the directional behaviour of the described cell populations and evaluate whether they migrate in a coordinate way and directed towards the centre of the wound. Net displacement angles have been used to compute the maximum likelihood estimate for parameters $\mu$ (mean direction) and $\mathrm{k}$ (direction concentration) of a von Mises distribution function. The calculated curves have been plotted overlaid onto the experimental data in Fig. 8D and 9D. For untreated (C) NIH3T3 and NIHRasV12 populations, unidirectional behaviour is indicated by a single peak centered around the expected angle $\left(0^{\circ}\right)$. The Watson test [25] was used to assess, for both von Mises and uniform distribution 
Sepe/Ferrari/Cantarella/Fioretti/Paolella: Ras Activated Pathways Differentially Affect Directional Migration

\begin{tabular}{lcccccc}
\hline & \multicolumn{5}{c}{ NIH3T3 } & \multicolumn{3}{c}{ NIHRasV12 } \\
& C & LY & PD & C & LY & PD \\
\hline & & & & & & \\
Mean direction & $-17.69+/-7.21$ & $2.01+/-6.93$ & $-31.63+/-34.85$ & $4.42+/-7.83$ & $27.11+/-9.18$ & $-18.57+/-31.81$ \\
Dir. concentration & $5.79+/-2.23$ & $7.36+/-3.16$ & $0.86+/-0.57$ & $4.66+/-1.68$ & $4.43+/-1.81$ & $0.84+/-0.51$ \\
von Mises fit & 0.025 & 0.034 & 0.030 & 0.048 & 0.045 & 0.020 \\
Crit. value (vM) & 0.164 & 0.164 & 0.110 & 0.158 & 0.158 & 0.110 \\
Circ. uniform fit & 0.630 & 0.563 & 0.081 & 0.662 & 0.494 & 0.087 \\
Crit. value (Cir) & 0.267 & 0.267 & 0.267 & 0.267 & 0.267 & 0.267 \\
\hline
\end{tabular}

Table 1. Evaluation of goodness of fit of von Mises and circular uniform distributions to the experimental data. The analysis was carried out for both NIH3T3 and NIHRasV12 under control (C) conditions, with LY and PD inhibitors. The directional concentration values (Dir. concentration) indicate the degree of concentration of angles around the mean (Mean direction). The von Mises hypothesis may be accepted when the von Mises fit value is below its critical value (Crit. value vM); the "circular uniform fit" hypothesis should be rejected when circular uniform fit (Circ. uniform fit) is above the indicated critical value (Crit. value $\mathrm{Cir}$ ). For both analyses the chosen significance level was 0.01 .

models, the goodness of fit of the calculated curve to experimental data: the results are reported in Table 1. For both cell lines, the low "von Mises fit" values confirm that the hypothesis may be accepted at the chosen significance level of 0.01 , while at the same level the "circular uniform fit" hypothesis, should be rejected because of the values well above the critical ones. The estimated parameters, reported in the same table 1, show that the angles are tightly concentrated (5.79 and 4.65) around the mean angles (-17.69 and 4.42), and these last are very close to the angle expected for cells moving towards the wound $\left(0^{\circ}\right)$. Blocking the PI3K pathway (LY) does not modify the directional cell behaviour (fig 8D), with mean direction values still concentrated and oriented towards the wound, and only the von Mises distribution closely fits the experimental data (Table 1). In presence of PD 98059, instead, estimated von Mises distributions become wide and flat (Fig. 9D, PD), with no clear directional concentration (Table 1). Goodness of fit analysis, for von Mises and uniform distributions, shows that both distributions fit well to experimental data, as indicated by values well below the critical values for $\mathrm{P}<0.01$, a result clearly indicative of absence of directional bias.

\section{Discussion}

The results reported in this work demonstrate that, in wound healing experiments, directional movement is an important, arguably the main, factor active in driving wound closure. Directional movement is strongly associated with the existence of a gap, as it is observed immediately after the wound stimulus, lasts until the gap remains open and disappears after its healing. Ras is deeply involved in regulating wound closure and determining this directional bias, and ERK is probably its key effector in this process.

Within this work, wound healing assays, performed on fibroblast monolayers, revealed a specific Ras induced migratory behaviour, as constitutive Ras activation (RasV12) in NIH3T3 fibroblasts results in faster wound closure, obtained by making cells move more quickly and in a different, more direct way. NIHRasV12 cells invade the free space as isolated units, unlike NIH3T3, which move together, almost as if in a sheet-like structure, and make little progress at each time step. These results imply a role for Ras activation in wound healing, possibly also within parental NIH3T3, as indicated by PD 98059 mediated wound closure inhibition; they are in line with previous studies on the healing of wounded keratinocyte and other epithelial monolayers, which show an involvement of Ras in accelerated re-epithelization [26-28]. 


\section{Cellular Physiology Cell Physiol Biochem 2013;31:123-142 \\ \begin{tabular}{ll|l} 
and Biochemistry & $\begin{array}{l}\text { DOI: 10.1159/000343355 } \\
\text { Publisnea onme-januarly 29, } 2013\end{array}$ & $\begin{array}{l}\text { O } 2013 \mathrm{~S} \text {. Karger AG, Basel } \\
\text { www.karger.com/cpb }\end{array}$ \\
\cline { 2 - 3 } Sepe/Ferrari/Cantarella/Fioretti/Paolella: Ras Activated Pathways Differentially Affect
\end{tabular} Directional Migration}

In wound healing assays, presence of free space, loss of cell-cell contacts, cell debris resulting from cell destruction, all play a role in the cellular response resulting in wound closure. Following a wound, pathways activated by extracellular stimuli such as FGF, HGF, EGF family growth factors, have all been shown to be involved in the response in epithelial cells, but also in fibroblasts $[29,30]$. These and other factors activate cell proliferation and migration, and cooperate to fill the space left open by the injury. Along these pathways, Ras often acts as an intracellular signal molecule, able to positively regulate proliferation rate and cell migration [31, 32]. In this work, constitutive Ras activation in NIHRasV12 fibroblasts, results in increased proliferation rates and also confers the ability to move with higher speed than the parental cell line, but neither can fully explain enhanced wound healing (Fig. 2). The strongest involvement of Ras was found to be related to the directional bias of movement: although the introduction of a wound in NIH3T3 and NIHRasV12 monolayers acts for both as a directional stimulus (see Fig. 3), the presence of RasV12 gives an advantage to transformed cells that move more effectively, along less tortuous paths, more clearly directed towards the empty space. This effect is more clearly visible in presence of low serum levels resulting in reduced speed as also shown by other reports [22]; under these conditions wound closure is severely impaired in NIH3T3 but still effective in NIHRasV12 cells. These data are in agreement with previous studies, which implicated Ras in controlling the ability to sense a chemical stimulus and migrate towards it. In particular, Sasaki 2004, showed that inhibition of Ras pathway in Dictyostelium determines reduced cell polarity and defective directional chemotaxis [33]; note that in that report directionality is meant as a measure of how straight cells move, the feature that we refer to as path linearity, i.e. the ratio of net displacement to path length (see Materials and Methods). As said, in populations moving after a wound, spatial sensing and directional response are not unique to Ras transformed fibroblasts, but they are enhanced by RasV12, as if in presence of two different activation levels of the Ras pathway: maximum and constitutively activated in NIHRasV12, lower and wound induced in NIH3T3 fibroblasts. The directional behaviour is, in fact, visible even at a distance from the wound in NIHRasV12 cell populations, while the parental NIH3T3 line is position dependent, as only cells immediately surrounding the wound move in a clearly directional way. The directional bias is strictly dependent on the wound: in randomly moving cells constitutive Ras activation, in itself, does not alter any of these features and both parental and transformed cell lines move with comparable linearity and in a non directional way. These results point to a role for Ras as the upstream component of an "intelligent sensor system", which detects the stimulus, analyzes and integrates information and finally induces directional migration.

Ras is known to exert its effects through the activation of downstream effectors. Within this work, two main pathways were analyzed, respectively involving ERK and PI3K, both known to play a role in the wound healing process [34, 35]. In NIH3T3 and NIHRasV12 fibroblasts the effects of the two pathways are clearly separable, with the directional movement dependent on the activation of ERK, but not PI3K mediated pathway. The multifunctional potential of these pathways has also been recently highlighted in skeletal muscle cell migrating following mechanical damage [36]. Moreover, a fervid literature associates duration and magnitude of ERK activation with cell motility and invasion [3739]. In wounded epithelial monolayers, two waves of ERK phosphorylation have been observed, one early and transient followed by a later and more sustained one [23]; cell to cell communication through tight junctions has been invoked as a way of propagating the wave to neighboring cells. Within this work, rapid ERK activation was observed in fibroblasts located close to the wound (Fig. 5), followed by a second broader activation peak 3-5 hours later. Previous wound healing experiments involved activated ERK in regulating cell migration: Matsubayashi and co-workers demonstrated that inhibition of ERK activation results in markedly reduced movement of the epithelial sheet in wound healing experiments [23] and in corneal endothelial cells ERK has also been shown to affect migration speed [40, 
41]. Our results confirm the overall ERK involvement in regulating migration speed, and highlight its unique role in determining directional migration. In fact, selective block of ERK activation by PD 98059 completely abolishes the directional component of cell migration and renders cells unable to directionally move towards the wound. This treatment abolishes their skill to react to the injury by organizing actin fibers towards the wound, but does not affect the ability to sense and respond to the wound, as the actin cytoskeleton still reacts by acquiring a polarized shape both in NIHRasV12 and NIH3T3 cells (data not shown).

These data are in line with other reports that implicate the ERK pathway in the formation of membrane structures required for cell migration and potentially involved in determining movement direction [42-44]. ERK signalling is known to contribute to membrane ruffling through transcriptional upregulation of Rac activator urokinase plasminogen receptor (UPAR) [45] and is temporally and spatially associated with integrin clustering in spreading cells, where it may play a role in regulating focal adhesion assembly [46]. Among ERK substrates, claimed to be responsible for ERK-induced peripheral effects, there are myosin light chain kinase (MLCK), involved in turnover of focal adhesions and extension of membrane protrusions [43], and calpain, a $\mathrm{Ca}^{++}$-activated proteolytic enzyme required for adhesion turnover [47]. Finally, ERK may regulate cellular motility by promoting specific gene transcription, including early and late responsive genes associated with lamellipodia extensions and tumor invasion [48].

Inhibition of PI3K pathway by LY 294002 affects speed at a degree similar to ERK inhibition, but exerts no effect on directional cell migration in wound healing (Fig.7 and 8). Previous studies in Dictyostelium discoideum and mammalian neutrophils showed that Ras may be rapidly and transiently activated in response to chemoattractant stimulation, and mediates leading edge formation by activating PI3K at the plasma membrane [33, 49-51]. PI3K activation and successive PIP3 production play a central role towards obtaining cell polarity and migration speed, but inhibition of this pathway is still compatible with efficient chemotaxis [52-55]. These reports are in line with the present data, which indicate that PI3K activation is not necessary for directional motility, although it is involved in controlling cell speed. Actin filament formation, large pseudopodia arrangement and fast movements towards chemoattractants are potentially involved in the process [56]. Speed modifications were often observed, as both NIH3T3 and NIHRasV12 cells move at higher speed after a wound, than when in unwounded monolayers, but this alteration is less specific, as more factors can contribute to determine it: as said, ERK and PI3K are both activated by Ras and both play a role in determining the increased speed observed after a wound. However, speed reductions, although appreciable, fail to block wound closure in low serum or when PI3K pathway is inhibited by LY 294002. In contrast Ras-ERK regulated directional movement appears to be the main force driving the process: only when ERK activation is blocked and directional bias is abolished, edge progression is clearly reduced.

Wound healing assays are often studied as a model system for in vivo wound repair, where fibroblasts play an important role in forming the granulation tissue. By using this assay a specific role may be given to Ras and its effectors in regulating directional migration. Directional motility is of course important in other situations, beyond wound healing, whenever motion towards a specific point is involved. During embryogenesis it is implicated in driving germ cells to correct locations, to form organs and to generate connections in development of the nervous system [57]. In the adult, directional migration has been implicated in physiological processes, such as immune cell trafficking and stem cell homing, but also in many pathological conditions $[58,59]$, as in metastasis formation, where the directional behaviour acquired by cancerous cells, makes them able to efficiently escape the primary tumour and reach a specific tissue [60]. Identification of the Ras-ERK pathway as a key mechanism in directional movement might be instrumental to the identification of molecular targets specifically responsible for controlling directional cell migration in such cases. 
Sepe/Ferrari/Cantarella/Fioretti/Paolella: Ras Activated Pathways Differentially Affect Directional Migration

\section{Acknowledgements}

We wish to thank Maria Vittoria Barone for the gift of NIHRasV12 and NIHSrc527 cell lines and for help in setting up the early phases of this work. We also thank Angelo Boccia for helpful discussions on some aspects of MotoCell development. L.S. was on a post doctoral fellowship from LITBIO project, MIUR, M.C.F. was a PhD student and later the recipient of a post doctoral fellow from Ceinge, Napoli and Dipartimento di Biochimica e Biotecnologie Mediche, Universita' degli studi di Napoli Federico II. C.C. was the recipient of a PhD fellowship from SEMM (European School of Molecular Medicine, Napoli and Milano); F.F. was on a PhD studentship from Ceinge, Napoli

This work has been supported by Ministero dell'Istruzione dell'Universita' e della Ricerca (MIUR) under the FIRB (LITBIO), PON Lab-GTP and PRISM.

\section{References}

1 Wennerberg K, Rossman KL, Der CJ: The ras superfamily at a glance. J Cell Sci 2005;118:843-846.

2 Rajalingam K, Schreck R, Rapp UR, Albert S: Ras oncogenes and their downstream targets. Biochim Biophys Acta 2007;1773:1177-1195.

-3 Pylayeva-Gupta Y, Grabocka E, Bar-Sagi D: Ras oncogenes: Weaving a tumorigenic web. Nat Rev Cancer 2011;11:761-774.

4 Jemal A, Siegel R, Xu J, Ward E: Cancer statistics, 2010. CA Cancer J Clin 2010;60:277-300.

5 Schubbert S, Shannon K, Bollag G: Hyperactive ras in developmental disorders and cancer. Nat Rev Cancer 2007; 7:295-308.

-6 Muschel RJ, Williams JE, Lowy DR, Liotta LA: Harvey ras induction of metastatic potential depends upon oncogene activation and the type of recipient cell. Am J Pathol 1985;121:1-8.

7 Bondy GP, Wilson S, Chambers AF: Experimental metastatic ability of h-ras-transformed nih3t3 cells. Cancer Res 1985;45:6005-6009.

-8 Greig RG, Koestler TP, Trainer DL, Corwin SP, Miles L, Kline T, Sweet R, Yokoyama S, Poste G: Tumorigenic and metastatic properties of "Normal" And ras-transfected nih/3t3 cells. Proc Natl Acad Sci U S A 1985;82:36983701.

-9 Fujimoto K, Sheng H, Shao J, Beauchamp RD: Transforming growth factor-beta1 promotes invasiveness after cellular transformation with activated ras in intestinal epithelial cells. Exp Cell Res 2001;266:239-249.

10 Gildea JJ, Harding MA, Gulding KM, Theodorescu D: Transmembrane motility assay of transiently transfected cells by fluorescent cell counting and luciferase measurement. Biotechniques 2000;29:81-86.

11 Ueoka Y, Kato K, Kuriaki Y, Horiuchi S, Terao Y, Nishida J, Ueno H, Wake N: Hepatocyte growth factor modulates motility and invasiveness of ovarian carcinomas via ras-mediated pathway. Br J Cancer 2000;82:891-899.

12 Nguyen DH, Catling AD, Webb DJ, Sankovic M, Walker LA, Somlyo AV, Weber MJ, Gonias SL: Myosin light chain kinase functions downstream of ras/erk to promote migration of urokinase-type plasminogen activatorstimulated cells in an integrin-selective manner. J Cell Biol 1999;146:149-164.

-13 Yip SC, El-Sibai M, Coniglio SJ, Mouneimne G, Eddy RJ, Drees BE, Neilsen PO, Goswami S, Symons M, Condeelis JS, Backer JM: The distinct roles of ras and rac in pi 3-kinase-dependent protrusion during egf-stimulated cell migration. J Cell Sci 2007;120:3138-3146.

14 Petrie RJ, Doyle AD, Yamada KM: Random versus directionally persistent cell migration. Nat Rev Mol Cell Biol 2009;10:538-549.

15 Jaeger S, Song Q Chen SS: Dynamik: A software environment for cell dynamics, motility, and information tracking, with an application to ras pathways. Bioinformatics 2009;25:2383-2388.

16 Martens L, Monsieur G, Ampe C, Gevaert K, Vandekerckhove J: Cell_motility: A cross-platform, open source application for the study of cell motion paths. BMC Bioinformatics 2006; 7:289.

17 DeNicola GM, Tuveson DA: Ras in cellular transformation and senescence. Eur J Cancer 2009;45:211-216.

18 Vial E, Sahai E, Marshall CJ: Erk-mapk signaling coordinately regulates activity of rac1 and rhoa for tumor cell motility. Cancer Cell 2003;4:67-79. 


\section{Cellular Physiology Cell Physiol Biochem 2013;31:123-142 \begin{tabular}{l|l} 
and Biochemistry Published onlIne: January 29, 2013 & $\begin{array}{l}\text { C 2013 S. Karger AG, Basel } \\
\text { www.karger.com/cpb }\end{array}$ \\
\hline
\end{tabular}}

Sepe/Ferrari/Cantarella/Fioretti/Paolella: Ras Activated Pathways Differentially Affect Directional Migration

19 Cantarella C, Sepe L, Fioretti F, Ferrari MC, Paolella G: Analysis and modelling of motility of cell populations with motocell. BMC Bioinformatics 2009;10:S12.

20 Batschelet: Circular stastistics in biology. Academic Press, London UK, 1981

21 Mardia: Statistics of directional data. Academic Press, New York 1972

-22 Kurten RC, Chowdhury P, Sanders RC Jr, Pittman LM, Sessions LW, Chambers TC, Lyle CS, Schnackenberg BJ, Jones SM: Coordinating epidermal growth factor-induced motility promotes efficient wound closure. Am J Physiol Cell Physiol 2005;288:C109-121.

23 Matsubayashi Y, Ebisuya M, Honjoh S, Nishida E: Erk activation propagates in epithelial cell sheets and regulates their migration during wound healing. Curr Biol 2004;14:731-735.

24 Bentley: Modelling circular data using a mixture of von mises and uniform distribution. Simon Fraser University 2006

25 Watson G: Goodness-of-fit tests on a circle. Biometrika 1961:109-114.

26 Tscharntke M, Pofahl R, Krieg T, Haase I: Ras-induced spreading and wound closure in human epidermal keratinocytes. FASEB J 2005;19:1836-1838.

27 Turchi L, Chassot AA, Rezzonico R, Yeow K, Loubat A, Ferrua B, Lenegrate G, Ortonne JP, Ponzio G: Dynamic characterization of the molecular events during in vitro epidermal wound healing. J Invest Dermatol 2002;119:56-63.

28 Tarnawski AS: Cellular and molecular mechanisms of gastrointestinal ulcer healing. Dig Dis Sci 2005;50:S2433.

29 Behm B, Babilas P, Landthaler M, Schreml S: Cytokines, chemokines and growth factors in wound healing. J Eur Acad Dermatol Venereol 2012;26:812-820.

-30 Nikolic DL, Boettiger AN, Bar-Sagi D, Carbeck JD, Shvartsman SY: Role of boundary conditions in an experimental model of epithelial wound healing. Am J Physiol Cell Physiol 2006;291:C68-75.

-31 Giehl K: Oncogenic ras in tumour progression and metastasis. Biol Chem 2005;386:193-205.

-32 Shima Y, Okamoto T, Aoyama T, Yasura K, Ishibe T, Nishijo K, Shibata KR, Kohno Y, Fukiage K, Otsuka S, Uejima D, Nakayama T, Nakamura T, Kiyono T, Toguchida J: In vitro transformation of mesenchymal stem cells by oncogenic h-rasval12. Biochem Biophys Res Commun 2007;353:60-66.

-33 Sasaki AT, Chun C, Takeda K, Firtel RA: Localized ras signaling at the leading edge regulates pi3k, cell polarity, and directional cell movement. J Cell Biol 2004;167:505-518.

-34 Fitsialos G, Chassot AA, Turchi L, Dayem MA, LeBrigand K, Moreilhon C, Meneguzzi G, Busca R, Mari B, Barbry P, Ponzio G: Transcriptional signature of epidermal keratinocytes subjected to in vitro scratch wounding reveals selective roles for erk1/2, p38, and phosphatidylinositol 3-kinase signaling pathways. J Biol Chem 2007;282:15090-15102.

-35 Tetreault MP, Chailler P, Beaulieu JF, Rivard N, Menard D: Epidermal growth factor receptor-dependent pi3k-activation promotes restitution of wounded human gastric epithelial monolayers. J Cell Physiol 2008;214:545-557.

-36 Al-Shanti N, Faulkner SH, Saini A, Loram I, Stewart CE: A semi-automated programme for tracking myoblast migration following mechanical damage: Manipulation by chemical inhibitors. Cell Physiol Biochem 2011;27:625-636.

-37 Krueger JS, Keshamouni VG, Atanaskova N, Reddy KB: Temporal and quantitative regulation of mitogenactivated protein kinase (mapk) modulates cell motility and invasion. Oncogene 2001;20:4209-4218.

-38 McCawley LJ, Li S, Wattenberg EV, Hudson LG: Sustained activation of the mitogen-activated protein kinase pathway. A mechanism underlying receptor tyrosine kinase specificity for matrix metalloproteinase- 9 induction and cell migration. J Biol Chem 1999;274:4347-4353.

39 Tian YC, Chen YC, Chang CT, Hung CC, Wu MS, Phillips A, Yang CW: Epidermal growth factor and transforming growth factor-beta1 enhance hk-2 cell migration through a synergistic increase of matrix metalloproteinase and sustained activation of erk signaling pathway. Exp Cell Res 2007;313:2367-2377.

40 Chen WL, Lin CT, Li JW, Hu FR, Chen CC: Erk1/2 activation regulates the wound healing process of rabbit corneal endothelial cells. Curr Eye Res 2009;34:103-111.

-41 Teranishi S, Kimura K, Nishida T: Role of formation of an erk-fak-paxillin complex in migration of human corneal epithelial cells during wound closure in vitro. Invest Ophthalmol Vis Sci 2009;50:5646-5652.

42 Huang C, Jacobson K, Schaller MD: Map kinases and cell migration. J Cell Sci 2004;117:4619-4628.

43 Klemke RL, Cai S, Giannini AL, Gallagher PJ, de Lanerolle P, Cheresh DA: Regulation of cell motility by mitogenactivated protein kinase. J Cell Biol 1997;137:481-492. 
Sepe/Ferrari/Cantarella/Fioretti/Paolella: Ras Activated Pathways Differentially Affect Directional Migration

-44 Wu WS, Wu JR, Hu CT: Signal cross talks for sustained mapk activation and cell migration: The potential role of reactive oxygen species. Cancer Metastasis Rev 2008;27:303-314.

45 Barros JC, Marshall CJ: Activation of either erk1/2 or erk5 map kinase pathways can lead to disruption of the actin cytoskeleton. J Cell Sci 2005;118:1663-1671.

46 Fincham VJ, James M, Frame MC, Winder SJ: Active erk/map kinase is targeted to newly forming cell-matrix adhesions by integrin engagement and v-src. EMBO J 2000;19:2911-2923.

-47 Glading A, Bodnar RJ, Reynolds IJ, Shiraha H, Satish L, Potter DA, Blair HC, Wells A: Epidermal growth factor activates m-calpain (calpain ii), at least in part, by extracellular signal-regulated kinase-mediated phosphorylation. Mol Cell Biol 2004;24:2499-2512.

48 Gialeli C, Theocharis AD, Karamanos NK: Roles of matrix metalloproteinases in cancer progression and their pharmacological targeting. FEBS J 2011;278:16-27.

49 Wilkins A, Insall RH: Small gtpases in dictyostelium: Lessons from a social amoeba. Trends Genet 2001;17:4148.

50 Sasaki AT, Firtel RA: Finding the way: Directional sensing and cell polarization through ras signalling. Novartis Found Symp 2005;269:73-87; discussion 87-91, 223-230.

51 Zhang S, Charest PG, Firtel RA: Spatiotemporal regulation of ras activity provides directional sensing. Curr Biol 2008;18:1587-1593.

52 Cai H, Devreotes PN: Moving in the right direction: How eukaryotic cells migrate along chemical gradients. Semin Cell Dev Biol 2011;22:834-841.

-53 Ferguson GJ, Milne L, Kulkarni S, Sasaki T, Walker S, Andrews S, Crabbe T, Finan P, Jones G, Jackson S, Camps M, Rommel C, Wymann M, Hirsch E, Hawkins P, Stephens L: Pi(3)kgamma has an important context-dependent role in neutrophil chemokinesis. Nat Cell Biol 2007;9:86-91.

54 Hoeller O, Kay RR: Chemotaxis in the absence of pip3 gradients. Curr Biol 2007;17:813-817.

55 Wessels D, Lusche DF, Kuhl S, Heid P, Soll DR: Pten plays a role in the suppression of lateral pseudopod formation during dictyostelium motility and chemotaxis. J Cell Sci 2007;120:2517-2531.

-56 Bosgraaf L, Keizer-Gunnink I, Van Haastert PJ: Pi3-kinase signaling contributes to orientation in shallow gradients and enhances speed in steep chemoattractant gradients. J Cell Sci 2008;121:3589-3597.

57 Laird DJ, von Andrian UH, Wagers AJ: Stem cell trafficking in tissue development, growth, and disease. Cell 2008;132:612-630.

58 Wang F: The signaling mechanisms underlying cell polarity and chemotaxis. Cold Spring Harb Perspect Biol 2009;1:a002980.

59 Jin T, Xu X, Hereld D: Chemotaxis, chemokine receptors and human disease. Cytokine 2008;44:1-8.

60 Condeelis J, Singer RH, Segall JE: The great escape: When cancer cells hijack the genes for chemotaxis and motility. Annu Rev Cell Dev Biol 2005;21:695-718. 